\title{
Is physical and psychological work stress associated with fatigue in Danish ferry ship employees?
}

\author{
Solveig Boeggild Dohrmann $₫$, Kimmo Herttua $₫$, Anja Leppin $₫$
}

Centre of Maritime Health and Society, Institute of Public Health, University of Southern Denmark (SDU Esbjerg), Esbjerg, Denmark

\begin{abstract}
Background: Fatigue is a recognised risk factor for safety in seafaring. While always dangerous, fatigue in ferry shipping is especially hazardous as it may jeopardise passengers' safety. To counteract fatigue, knowledge on its determinants is important. Little, however, is known on the influence from physical and psychosocial work environment factors within ferry shipping. The aim of the study was to investigate the association between work stress in terms of physical stressors, perceived job demands and job control and different dimensions of fatigue among ferry ship employees and to test whether a potential effect of work stress was mediated by sleep satisfaction.

Materials and methods: The design was cross-sectional. 193 respondents answered to a self-administered questionnaire including standardised scales, i.e. the Swedish Occupational Fatigue Inventory and the Copenhagen Psychosocial Questionnaire for job demands and control. The association of risk factors with fatigue was determined using hierarchical multiple linear regression analyses.

Results: Physical work stressors were positively associated with only one of five fatigue subscales: lack of energy. Higher levels of demands were related to more lack of energy, lack of motivation, physical exertion and sleepiness, while more control was related to lesser lack of energy, lack of motivation and sleepiness. No demand-control interaction was found. Effects of demand and control were partly mediated by sleep satisfaction.

Conclusions: Although limited by its cross-sectional design this study provides support for the independent relevance of demands and control for employee fatigue in ferry shipping and for a mediating role of sleep satisfaction.

(Int Marit Health 2020; 71, 1: 46-55)

Key words: fatigue, demand-control model, job demands, job control, psychosocial work environment, sleep satisfaction, seafaring, seafarers
\end{abstract}

\section{INTRODUCTION}

Fatigue is a recognised problem in an occupational context [1-3]. It refers to ‘a state of an organism's muscles, viscera, or central nervous system, where prior physical activity and/or mental processing, in the absence of sufficient rest, results in insufficient cellular capacity or system wide energy to maintain the original level of activity and/or processing by using normal resources' [3]. Symptoms range from minor and quick to resolve by sufficient rest to severe and hard to alleviate or chronic [3].

In the working population the more chronic type of fatigue has been associated with impairments comparable to those of patients with chronic disease (e.g. fibromyalgia and temporomandibular joint dysfunction); physical discomfort, pain and memory and/or cognitive degradation [3, 4], resulting in sickness absenteeism and work disability [5, 6]. Furthermore, fatigue is a risk factor for occupational safety, particularly in the transport industry [3] including shipping [3, 7-11]. Fatigue in ferry shipping is especially hazardous as it may jeopardise passengers' safety [12, 13]. Almost $89 \%$ of ferry crew members reported that tiredness had led to loss of concentration while at work, up to one third had been involved in a fatigue-related incident or accident and a little less than one fourth had fallen asleep at work more than once a month $[13,14]$. These rates are comparable to those in other transportation sectors $(76 \%$

Postdoc Solveig Dohrmann, PhD, Centre of Maritime Health and Society, Department of Public Health, University of Southern Denmark, Niels Bohrs Vej 9 , 6700 Esbjerg, Denmark, tel: 00456550 4242, e-mail: sbdohrmann@sdu.dk 
in seafaring [15], 71\% in road transportation [16], 75-90\% in aviation [17]) but considerably higher than the 16-38\% reported from the general work force [18-20].

A first step towards counteracting this problem by preventive programmes is acquiring knowledge about factors determining fatigue in seafaring $[7,8]$. Recent systematic reviews on fatigue in seafarers found most evidence to be available for proximal influence factors, such as sleep deprivation and irregular work-rest scheduling $[8,21,22]$. In contrast, the role of specific work tasks and working conditions, including the physical and psychosocial working environment has been investigated by too few studies to provide any conclusive evidence [21]. However, these factors have been consistently linked to fatigue in onshore working populations [18, 23-25].

According to the Demand-Control model [26], which has been widely used in international research on occupational stress since the 1980s, strain results from the experienced level of job demands as well as the level of control over tasks and the way they are performed [25-27]. The impact can occur either due to main or buffer effects. According to the former, high strain results separately from either high demands or low control or both, while the latter predicts that high demands lead to strain only when perceived control is low [26].

To the authors' knowledge no study has yet applied the Demand-Control model in ferry shipping and no studies have tested the suggested buffering effect in a seafaring context. However, a recent study tested the effect of job demands in seafarers working on board cargo ships, container ships and passenger lines and found high job demands to be associated with physical symptoms (e.g. gastrointestinal discomfort) and unhealthy behaviours (e.g. smoking) [28]. Yet another study used the main effects model in seafarers of supply vessels for the oil and gas industry and found high levels of demands as well as low levels of control associated with more fatigue [29]. However, this specific subgroup of employees may not be representative for seafarers in general.

High levels of job demand and/or low levels of job control have an adverse influence on sleep quality in landbased occupations [23]. Furthermore, the body of literature has shown that sleep deprivation and/or poor-quality are associated with higher levels of fatigue among seafarers $[8,21,22]$, and it supports a mediating effect from sleep quality on other outcomes than fatigue in onshore settings (e.g. sleep fragmentation has been found to mediate the relationship between social climate and psycho-somatic complaints among full time employees in finance, health care and management [30]). Despite this, to date, a potential mediating effect from sleep-related factors on fatigue has yet to be tested in an onshore- as well as in a seafaring context.
The objective of the present article was therefore to investigate if physical work environment stressors as well as perceived job demands, and job control had an additive effect on different dimensions of fatigue among crew members and terminal workers in Danish ferry shipping. Further, an interactive effect between job demands and job control on the different dimensions of fatigue was tested. Finally, it was investigated whether a potential effect of work stress is mediated by sleep satisfaction.

\section{MATERIALS AND METHODS}

The present study was based on a cross-sectional survey design, using a standardised questionnaire battery for data collection. The checklist 'Strengthening the Reporting of Observational Studies in Epidemiology' was used for guidance of reporting [31].

\section{PARTICIPANTS AND PROCEDURE}

Participants were recruited from two Danish ferry ship companies; Company 1 operating five domestic and two internationals services (all services were included in the study) and Company 2 operating three international services (one service was included into the study). Data was collected from April to the end of September 2015. Ferry ships were laid up overnight meaning that most crew members slept at home (though still on call during their service periods), alternatively in onshore watch rooms. Therefore, preconditions, such as sleeping environments and schedules (including working early mornings, evenings and late nights) were mostly similar and both groups were considered eligible for the study and invited for participation via written information materials. The questionnaire was made available to 513 employees, electronically on the companies' intranet as well as in a printed form; Company $1: n=281$ and Company $2 ; n=232$ (179 terminal workers and 334 crew members), and 193 employees returned a completed questionnaire yielding a response rate of $56 \%$ and $16 \%$, respectively. Characteristics of the study population are presented in Table 1.

The study was approved by the Danish Data Protection Agency [32]. According to Danish law questionnaire surveys like the one used in the present study do not need approval from an ethics committee (§14) [33], and consent to participate was given by 'explicit enactment', i.e. by submitting the questionnaire (§3) [32, 34].

\section{MEASUREMENT \\ Outcome}

Fatigue was assessed using the second version of the Swedish Occupational Fatigue Inventory (SOFI) [1]. The English version was translated into Danish using the translation/back-translation technique [35]. SOFI includes 20 symptoms of fatigue to be rated on response scales from 
Table 1. Characteristics of the study population and the working environment

\begin{tabular}{|c|c|c|c|c|}
\hline & Number & Per cent & Mean & SD \\
\hline Age & 172 & & 47.6 & 12.4 \\
\hline Gender (female) & 19 & 11 & & \\
\hline \multicolumn{5}{|l|}{ School education } \\
\hline$\geq 7^{\text {th }}$ grade - technical school & 90 & 57 & & \\
\hline Gymnasium education & 68 & 43 & & \\
\hline \multicolumn{5}{|l|}{ Professional education } \\
\hline Vocational training & 77 & 45 & & \\
\hline University college and university & 94 & 55 & & \\
\hline \multicolumn{5}{|l|}{ Professional group } \\
\hline Officers & 102 & 53 & & \\
\hline Non-officers & 91 & 47 & & \\
\hline Living with a partner (yes) & 135 & 78 & & \\
\hline Children under 6 years old (yes) & 25 & 15 & & \\
\hline \multicolumn{5}{|l|}{ Ferry ship company } \\
\hline Company 1 & 156 & 81 & & \\
\hline Company 2 & 37 & 19 & & \\
\hline \multicolumn{5}{|l|}{ Workplace } \\
\hline Terminal & 34 & 18 & & \\
\hline Ferry ship & 158 & 82 & & \\
\hline Number of workdays per week & 179 & & 3.85 & 0.90 \\
\hline \multicolumn{5}{|l|}{ Typical time of work } \\
\hline Day and evening & 96 & 52 & & \\
\hline Day, evening and night & 89 & 48 & & \\
\hline Sleeping at the workplace/on board (yes) & 72 & 45 & & \\
\hline \multicolumn{5}{|l|}{ Physical activity } \\
\hline $0-4$ hours per week, low intensity & 53 & 31 & & \\
\hline$\geq 2$ hours per week, high intensity & 119 & 69 & & \\
\hline Smoking (yes) & 43 & 25 & & \\
\hline Sleep satisfaction (1 [low] - 10 [very high]) & 167 & & 6.42 & 2.34 \\
\hline $\begin{array}{l}\text { Disturbance by the physical work environment } \\
\text { (1 [low disturbance] }-5 \text { [high disturbance]) }\end{array}$ & 189 & & 2.07 & 0.71 \\
\hline Job demands (0 [low] - 25-50-75-100 [high]) & 184 & & 48.86 & 14.18 \\
\hline Job control (0 [low] - 25-50-75-100 [high]) & 185 & & 48.78 & 18.10 \\
\hline SOFI - Lack of energy (0 [very low] - 6 [very high]) & 166 & & 2.02 & 1.55 \\
\hline SOFI - Physical exertion (0 [very low] - 6 [very high]) & 166 & & 1.21 & 1.31 \\
\hline SOFI - Physical discomfort (0 [very low] - 6 [very high]) & 166 & & 1.48 & 1.43 \\
\hline SOFI - Lack of motivation (0 [very low] - 6 [very high]) & 166 & & 1.56 & 1.45 \\
\hline SOFI -Sleepiness (0 [very low] - 6 [very high]) & 166 & & 1.79 & 1.40 \\
\hline
\end{tabular}

SOFI - Swedish Occupational Fatigue Inventory; SD - standard deviation

$0=$ 'not at all' to $6=$ 'to a very high degree' with regard to how respondents felt when they had been most tired at work during the last 4 weeks. The instrument involves five sub-dimensions: 1) lack of energy (LE), 2) physical exertion (PE), 3) physical discomfort (PD), 4) lack of motivation (LM), and 5) sleepiness (S) with four items each [1]. A sum score 
was calculated for each of the five subscales [1]. Cronbach's alphas for the subscales ranged from 0.86 to 0.93 .

\section{Exposures}

Demand and control were assessed by four subscales of the Copenhagen Psychosocial Questionnaire (COPSOQ) a validated Danish counterpart to the Job Content Questionnaire [36] ('quantitative demands' [4 items], 'work pace' [3 items], 'influence at work' [4 items], and 'opportunities for professional development' [4 items]). All 15 items were to be rated either on a 5-point scale indicating frequency ('always' to 'almost never/never') or agreement ('to a very large extent' to 'to a very small extent'). 'Quantitative demands' and 'work pace' were then added up to a total 'job demands'-scale while 'influence at work' and 'opportunity for professional development' were summed up to a summary 'job control'-scale [36]. Cronbach's alphas ranged from 0.79 to 0.82 . To test the interaction between job demands and job control the two variables were first centred and then multiplied.

\section{Covariates}

Socio-demographic characteristics, such as age, gender, country of birth, school education (technical college/ /gymnasium education), professional education (vocational training/university college and university) and living with a partner (no/yes) were considered as standard covariates. Also, professional group (officers/non-officers), ferry ship company (company 1/2), workplace (ship/terminal), number of workdays per week, night work (no night work/night work [indicating shift work]), sleeping at the workplace (yes/no), children under six living at home (no/yes), physical activity (0-4 hours per week, low intensity/ $\geq 2$ hours per week, high intensity) and smoking (no/yes) were tested [11, 22, 23, 37]. Satisfaction with sleep was assessed via a 10-point rating scale (from 'completely satisfied' to 'not satisfied at all'). Finally, five single-item questions were used for measuring physical work environment stressors (noise, vessel movements, vibrations, heat, cold) based on 5-point frequency rating scales ('almost all the time' to 'almost never'). The five measures were combined into an overall index, i.e. a sum-up score of all five items [11, 21, 22, 37].

\section{DATA ANALYSIS}

When summing up scores for the SOFI- and COPSOQ-subscales missing values were replaced by individual subscale means in accordance with the instrument's guidelines $[1,36]$. Point-biserial and Pearson correlations were used to determine bivariate associations between fatigue scores and potentially associated variables, and the results are presented in Table 2. Age, gender and those individual or job characteristics which had been associated with at least one fatigue dimension on the bivariate level $(p<0.05)$, were included as potential confounding factors in the multivariable analyses. The only exception to this was 'vocational education'. Since this variable was highly correlated with 'professional group', only the latter factor was included in the subsequent analyses.

Prior to multivariable analyses, potential violations of assumptions in terms of linearity, multivariate normality, homoscedasticity and multicollinearity were checked for. Between 0 and 7 multivariate outliers were detected (standard residual $>3$ standard deviations), and the respective cases were removed from the final models, leaving the sample size ranging from $n=193(L E, L M, S)$ over $n=191$ (PD) to $n=186$ (PE).

Five models were designed for the prediction of the five fatigue dimensions. On step one, age, gender and those individual or job characteristics which had been associated with one of the fatigue dimensions on the bivariate level $(p<0.05)$ were adjusted for. Environmental stressors, job demands, job control and the demand-control interaction term were entered on step 2 (Table 3, Model 1 ).

To additionally test for a mediating effect of sleep satisfaction, another hierarchical model with the same covariates was run for predicting sleep satisfaction (Table 3, Model 1), after which sleep satisfaction was entered as a final variable into all five regression equations for the fatigue sub-dimensions (Table 3, Model 2). Age, sleep satisfaction, physical environment stress, job demands, and job control were entered as continuous, all others as binary variables. All analyses were conducted with SPSS Statistics 24.

\section{RESULTS}

Ninety-eight per cent of the study population were Danish citizens, $89 \%$ of whom were male, and mean age was 47.6 (range from 19 to 70) (Table 1). Approximately 50\% were officers, $80 \%$ were working on board of ferries, and for $50 \%$ typical work time involved night shifts. Disturbance by the physical working environment was low to moderate on average while mean scores for demand and control were in the medium range, and for fatigue at the lower end of the scale.

As data came from individual employees nested within different organisational units (terminals and ships), multilevel analyses might have been required. Mixed effect null models showed that a maximum of $4 \%$ of the variance in fatigue could be attributed to between cluster differences (intra-class correlations: $\mathrm{LE}=0.016, \mathrm{PE}=0.00, \mathrm{PD}=0.021$, $\mathrm{LM}=0.04, \mathrm{~S}=0.02)$. Due to these low coefficients, standard multiple hierarchical linear regression was used [38].

In the initial model, physical stressors were positively associated with lack of energy $(\beta=0.23)$, physical exertion $(\beta=0.23)$, physical discomfort $(\beta=0.25)$ and sleepiness 
Table 2. Bivariate correlations between personal characteristics, worksite characteristics, work stressors and different dimensions of fatigue

\begin{tabular}{|c|c|c|c|c|c|}
\hline & $\begin{array}{l}\text { SOFI - Lack } \\
\text { of energy }\end{array}$ & $\begin{array}{l}\text { SOFI - Physical } \\
\text { exertion }\end{array}$ & $\begin{array}{l}\text { SOFI - Physical } \\
\text { discomfort }\end{array}$ & $\begin{array}{l}\text { SOFI - Lack } \\
\text { of motivation }\end{array}$ & $\begin{array}{l}\text { SOFI- } \\
\text { Sleepiness }\end{array}$ \\
\hline Age & -0.02 & -0.05 & -0.08 & -0.13 & -0.13 \\
\hline Gender $^{1}$ & 0.10 & 0.02 & $0.21 * *$ & 0.06 & 0.14 \\
\hline School education ${ }^{2}$ & 0.05 & -0.04 & 0.01 & 0.03 & 0.05 \\
\hline Professional education ${ }^{3}$ & -0.11 & -0.06 & $-0.20 *$ & -0.12 & $-0.16^{*}$ \\
\hline Professional group 4 & 0.14 & 0.06 & $0.21 * *$ & 0.13 & $0.18 *$ \\
\hline Living with a partner ${ }^{5}$ & 0.04 & 0.10 & 0.11 & 0.01 & 0.07 \\
\hline Children under 6 years ${ }^{6}$ & -0.12 & -0.06 & -0.10 & -0.07 & -0.07 \\
\hline Ferry ship company ${ }^{7}$ & 0.09 & 0.02 & 0.13 & 0.04 & 0.10 \\
\hline Workplace ${ }^{8}$ & -0.13 & -0.09 & $-0.16^{*}$ & -0.14 & $-0.20 *$ \\
\hline Number of workdays per week & -0.08 & -0.04 & 0.07 & -0.13 & -0.06 \\
\hline Typical work time 9 & $0.20 *$ & $0.16^{*}$ & $0.26 * *$ & $0.17 *$ & $0.19 *$ \\
\hline Sleeping at the workplace/on board ${ }^{10}$ & -0.12 & -0.08 & -0.13 & -0.13 & -0.15 \\
\hline Physical activity ${ }^{11}$ & -0.10 & 0.01 & -0.04 & -0.04 & -0.07 \\
\hline Smoking ${ }^{12}$ & 0.05 & 0.02 & 0.07 & 0.02 & -0.01 \\
\hline Sleep satisfaction & $-0.50 * *$ & $-0.38 * *$ & $-0.42 * *$ & $-0.50 * *$ & $-0.56 * *$ \\
\hline Disturbance from the physical work environment & $0.39 * *$ & $0.26^{* \star}$ & $0.33^{* *}$ & $0.26 * \star$ & $0.30 * *$ \\
\hline Job demands & $0.40 * * *$ & $0.30 * * *$ & $0.27 * * *$ & $0,34 * * *$ & $0.36 * * *$ \\
\hline Job control & $-0.25 * *$ & $-0.20 *$ & $-0.17 *$ & $-0.30 * *$ & $-0.27 * *$ \\
\hline SOFI - Lack of energy & 1 & $0.66 * * *$ & $0.70 * * *$ & $0.80 * * *$ & $0.82^{* * *}$ \\
\hline SOFI - Physical exertion & $0.66 * * *$ & 1 & $0.67 * * *$ & $0.74 * * *$ & $0.72 * * *$ \\
\hline SOFI - Physical discomfort & $0.70 * * *$ & $0.67 * * *$ & 1 & $0.60 * * *$ & $0.67 * * *$ \\
\hline SOFI - Lack of motivation & $0.80 * * *$ & $0.74 * * *$ & $0.60 * * *$ & 1 & $0.84 * * *$ \\
\hline SOFI - Sleepiness & $0.82 * * *$ & $0.72^{* * *}$ & $0.67 * * *$ & $0.84 * * *$ & 1 \\
\hline
\end{tabular}

$*$ Significant value: $p<0.05 ; * *$ Significant value: $p<0.01 ; * * *$ Significant value: $p<0.001$; SOFI - Swedish Occupational Fatigue Inventory

${ }^{1}$ Female $=2 ;{ }^{2}$ Primary school $=1$, secondary school $=2 ;{ }^{3}$ Vocational training $=1$, university college $/$ university $=2 ;{ }^{4}$ Officers $=1$, non-officers $=2 ;{ }^{5}$ Yes $=2 ;{ }^{6}$ Yes $=2 ;$ ${ }^{7}$ Company $1=1$, Company $2=2 ;{ }^{8}$ Terminal $=1$, ferry ship $=2 ;{ }^{9}$ Day and evening $=1$, day, evening and night $=2 ;{ }^{10}$ Yes $=2 ;{ }^{11} 0-4$ hours per week $/$ low intensity $=1$, $\geq 2$ hours per week/high intensity $=2 ;{ }^{12}$ Yes $=2$

$(\beta=0.17)$. Job demands were positively associated with lack of energy, physical exertion, lack of motivation and sleepiness after controlling for potential confounders (LE, $\beta=0.33$; PE, $\beta=0.21$; LM, $\beta=0.32$; S, $\beta=0.31$; Table 3 , Model 1) while negative associations with the same subscales were found for job control (LE, $\beta=-0.26$; PE, $\beta=-0.24$; LM, $\beta=-0.36$; S, $\beta=-0.28$ ). In contrast, for none of the outcomes did the findings suggest an interaction between job demands and job control.

Testing additionally for associations between job-related stress and sleep satisfaction showed that perceived stress from the physical environment and job demands were negatively $(\beta=-0.19, \beta=-0.22)$ and job control positively associated with perceived sleep quality $(\beta=0.22)$. No indication for a demand-control interaction was found (Table 3, Model 1).
Adding sleep satisfaction to the models predicting fatigue showed a significant association of this factor with all five aspects of fatigue, indicating that higher subjective sleep quality was associated with less experience of fatigue (Table 3, Model 2). In these final models, physical-environment work stressors were only associated with lack of energy ( $\beta=0.16)$, physical exertion $(\beta=0.18)$ and physical discomfort $(\beta=0.20)$. Higher levels of perceived demands were still significantly associated with more lack of energy $(\beta=0.25)$, lack of motivation $(\beta=0.25)$, and sleepiness $(\beta=0.23)$. Similarly, more job control was related to lesser lack of energy $(\beta=-0.19)$, physical exertion $(\beta=-0.18)$, lack of motivation $(\beta=-0.28)$ and sleepiness $(\beta=-0.19)$. Again, there was no indication of a demand-control interaction.

Comparing prior findings for the association between work stress factors and fatigue without adjustment for sleep 


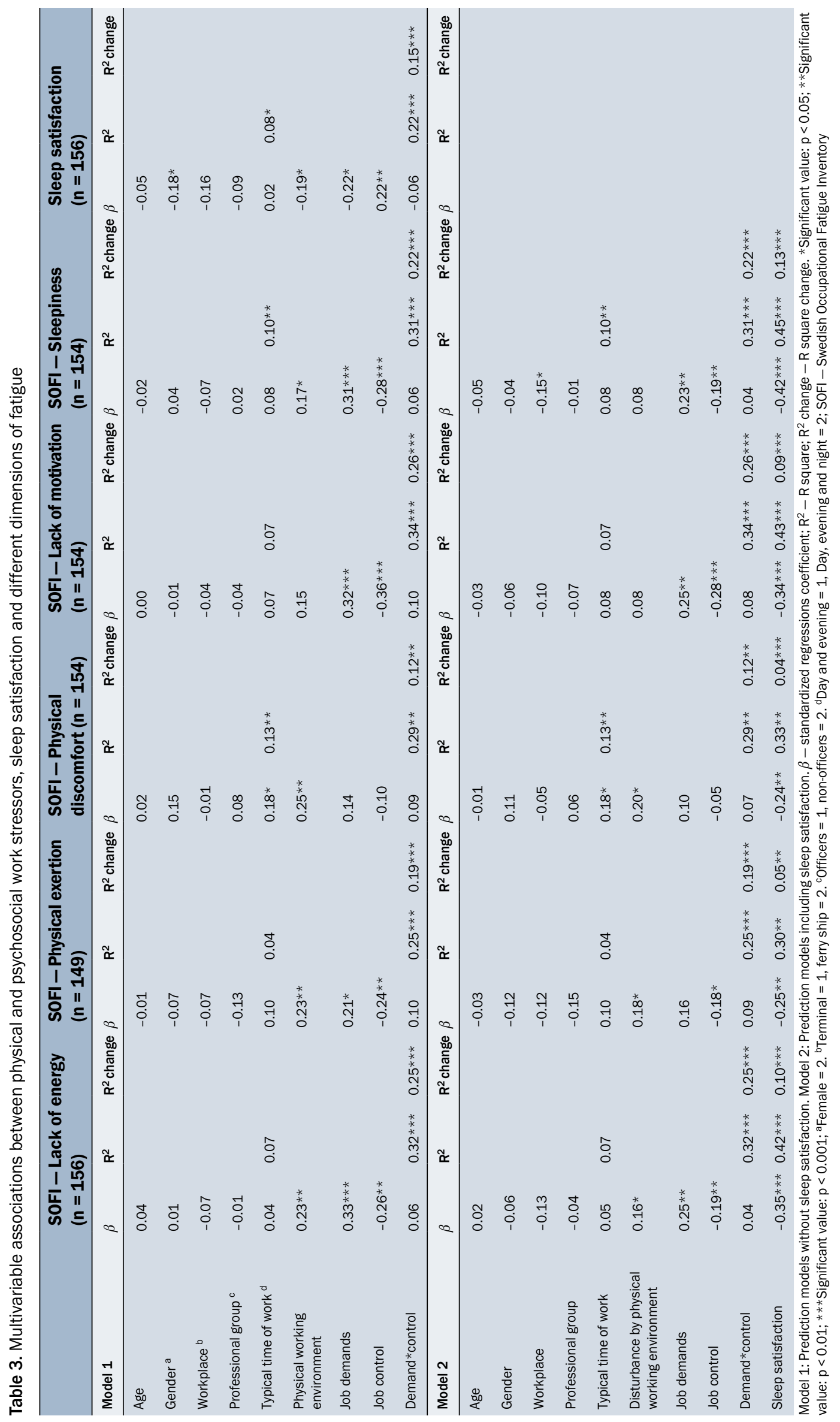


satisfaction (Table 3, Model 1) and subsequent findings after adjustment (Table 3, Model 2) showed that in particular the significant associations for demand and control with the different aspects of fatigue remained but were reduced in size. Adding sleep satisfaction to the models significantly increased explained variance in all fatigue sub-dimensions (Table 3, Models 1 and 2) by 4\% (PD) to 13\% (S) with overall explained variance ranging between $30 \%$ (PE) and 45\% (S).

\section{DISCUSSION}

This study aimed to test additive and interactive effects of work stress levels on different dimensions of fatigue and revealed supportive evidence only for additive effects. Effects tended to be stronger for psychological than for physical aspects of fatigue and adding sleep satisfaction improved predictive power while reducing the effect sizes for job demands and control, suggesting that parts of the effects of perceived job demands and control are mediated via sleep quality.

\section{LIMITATIONS OF THE STUDY}

Given the cross-sectional design of the study the observed associations are not interpretable as cause-effect associations. Thus, to which extent perceived demands and control increase fatigue or higher levels of fatigue contribute to perception of higher demands and lower experience of control or - most likely - there is a genuine reciprocal influence, cannot be determined. Causal ambiguity is also created by using a self-report questionnaire, and self-report measures are known to be prone to biases such as recall bias, social desirability bias and negative affectivity [39]. Thus, for instance, respondents with higher fatigue problems might be more likely to recall and report high demands and low control and vice versa. Moreover, it cannot be excluded that respondents in general underreported fatigue since high fatigue levels at work are considered problematic, even though all participants were assured confidentiality of data and were able to submit their responses without personal identification. A further limiting factor is the response rate since in particular the low response of employees from Company 2 implies the possibility of selection effects in terms of non-response/selective response and thereby potentially biased results [40]. Despite assurances of confidentiality it cannot be excluded that some of those with higher fatigue or more work stress were more reluctant to participate in the survey while reverse effects, i.e. employees with higher dissatisfaction being more motivated to participate in a work-place survey have also been known. As for external validity the low participation rate in Company 2 and in general of those working the terminals are limiting the generalisability of the study findings. Still, it should be noted that 1 ) other characteristics of the study sample (males in their later forties, half of whom were officers and for half of whose typical worktime involved night shifts) are in line with those of the general population of crew members working in Danish ferry shipping [41], and 2) that comparison of study participants and the total of employees did not show any significant difference in terms of age, gender, rank or working at a terminal versus on board ferry ships.

\section{THE ROLE OF JOB DEMANDS AND JOB CONTROL}

Findings from the present study are consistent with the assumption of an association between physical and psychosocial work stressors and fatigue in Danish ferry shipping employees. Perceived job demands, and job control were generally more important than disturbance from the physical working environment, which may reflect a general tendency in seafaring towards a reduction of strenuous manual labour performed primarily outdoors in inclement conditions. In the same vein, it is notable that the potential impact of job demands, and control was primarily expressed in terms of lack of energy, lack of motivation and sleepiness rather than physical exertion or discomfort [1]. This too indicates that ferry shipping nowadays might be more mentally than physically fatiguing [42], given a context characterised by time pressure and late and/or shifting working hours.

In accordance with the strain hypothesis of the demand-control model [26] results from the present study clearly support an additive effect of job demands and job control on fatigue; especially the psychological fatigue dimensions and sleepiness. No support was found for the buffer hypothesis since there was no indication of an interaction effect. This agrees with findings from many other studies in the occupational field as documented by a series of reviews $[25,27,43]$. However, it remains unclear to which extent this prevalent lack of buffering effects may be due to conceptual limitations. It has been suggested that there must be a close match between the type of demands and the available coping resource for buffering to occur [44], while broader types of measures such as the ones used in the present as well as many other studies might have problems detecting such effects [25, 27]. Interpreting present results in this light, it is suggested that a general sense of control might not be an adequate resource to buffer the effect from job demands on fatigue in a highly regulated workplace where all tasks are subjected to strict time schedules. In such circumstance's decision latitude, while still important, as reflected in the main effect found, may have less impact on the level of task demands, which might make buffering more difficult. As outlined in the introduction section, findings from other studies, though still few, suggest that psychosocial factors are linked to fatigue in ferry shipping as well as in other sectors of the seafaring industry $[8,21$, $22,28,29]$. As occupations and activities undertaken in 
this industry are various, heterogeneity in psychosocial and/or fatigue profile across sectors-is possible $[3,45]$. This is further supported by considering that psychosocial factors, like job demands and job control, originate from highly specific social structures and contexts [46, 47], as well as fatigue measurement may hinge upon the interpretation of words presented in measurement tools and/or depend on the interpretation of fatigue-related signs [3]. However, studies that investigate heterogeneities in profiles and associations between factors in a seafaring context are seemingly still lacking, and therefore it remains uncertain to what extent ferry crew members show different associations as compared to other sea- or land-based occupational groups. Therefore, it is important that future knowledge on psychosocial working conditions and fatigue in seafaring is derived from studies that allow for 1 ) an investigation of a more complex and specific nature of occupation-specific work factors and their relationship with fatigue, and 2) a comparison between type of ships and/or groups of seafarers $[11,48]$.

\section{THE ROLE OF SLEEP SATISFACTION}

As expected, lower job demands and higher job control were associated with higher subjective sleep satisfaction, while sleep satisfaction again attenuated the relation between job demands, job control and fatigue suggesting that a potential effect of these factors on fatigue is partly mediated by sleep quality. Associations between sleep deprivation/poor sleep quality and higher levels of fatigue have been recognised in other types of seafaring than ferry shipping $[11,21]$ and in other occupational branches [3, 24]. In a prospective study examining the causal direction of longitudinal relations between job demands, job control, sleep quality and fatigue among blue- and white-collar workers, higher demands over time were related to increased sleep complaints, while higher levels of job control led to fewer complaints [23]. Moreover, workers exposed to an increasing amount of high-strain work over time reported more sleep complaints, which also increased over time, while this was not the case for their counterparts in stable low strain or active jobs [23]. It is certainly plausible that a stressful psychosocial work environment negatively affects sleep, which again results in feelings of fatigue. However, fatigued employees are also likely to perceive work tasks as more demanding or to experience less control, thus reinforcing prior levels of fatigue.

It is interesting to note, though, that while sleep satisfaction was a mediator, it did not account for the whole association between job strain and fatigue, suggesting further pathways such as demotivation or burnout processes and/or differences in individual coping resources or actual coping behaviour when it comes to dealing with stressors, such as job demands [49]. Recently two studies have investigated resilience and perceived stress among merchant seafarers, and this concept was found to be cross-sectionally associated with and identified as a predictor of perceived stress (two point of measurement; 10 months follow up) $[50,51]$. Therefore, untangling the complex nature of these pathways seems of great importance. It requires future studies using a greater variety of outcomes and longitudinal designs. However, such studies are not common in seafaring yet and they are also difficult to implement in this research area [21, 22].

\section{IMPLICATIONS}

The relative low fatigue levels found in this study may suggest that there is a limited need for fatigue-mitigation in the Danish ferry shipping industry. However, variations in fatigue levels may suggest that some sub-groups still require interventions, for instance those working in the terminal and/or non-officers. Further, fatigue has been found to rise over time of duty, also in ferry shipping [9, 42, 48], and even fatigue levels that are not critically high from a perspective of individual health and well-being can endanger the safety of the crew and passengers $[3,7]$. In addition, the present study mainly focused on services where ferry ships were laid up overnight. Fatigue-profiles may differ between non- and overnight services, suggesting future studies to (also) include ferry ships with complete nightshift to investigate this in greater details.

\section{Job demands and job control}

Results from this study indicate that demand-reducing and control-supporting initiatives should be included into such strategies. Based on research in onshore occupations, ferry shipping companies are encouraged to focus future fatigue-prevention initiatives around staffing adequacy (e.g. adding manpower during peak times) [52-54], task variety (e.g. rotating schemes) [52-54], flexibility in working arrangements (e.g. participation in duty roster planning) [55] and participation in workplace decision making (e.g. in planning of demand-reducing and control-enforcing initiatives) [52-54], which have been found to have a posive impact on perceived job demands and job control.

\section{Sleep satisfaction}

Besides job demands and job control it seems that there is a need for also including sleep-related initiatives into fatigue-preventive strategies. In fact, sleep is an important factor to human health, and lack of sleep and poor sleep quality have been associated with risk of stress and strain among workers, including seafarers [8, 11, 21, 22]. Further, evidence has shown that the psychosocial work environ- 
ment is relevant for sleep. For instance, in accordance with the results of the present study high levels of job demands and lower levels of job control have been found to have an adverse influence on sleep quality [23]. While there is general evidence in favour of psychosocial and health effects of workplace interventions [52-54], there is still a need for more research testing the impact of changes in the psychosocial work environment on sleep quality. Given positive findings, ferry ship companies might be encouraged to consider specific sleep promoting initiatives, such as offering more comfortable beds in cabins/rooms with little noise and shift-systems that support intra- (e.g. in terms of napping) and inter-shift (e.g. sufficient time between shifts) recovery $[56,57]$.

\section{CONCLUSIONS}

Thus, although limited by its cross-sectional design this study provides support for the independent relevance of demands and control for employee fatigue in ferry shipping and for a mediating role of sleep satisfaction. Therefore, if these findings can be confirmed by longitudinal studies, companies could be encouraged to implement demand-reducing, and control and sleep supporting initiatives, for instance in form of engaging employees in duty roster-planning in combination with comfortable beds in sleep cabins/ /watch rooms that support intra- and inter-shift recovery. Furthermore, to support effective future fatigue prevention programmes, studies are needed which investigate a wider range of psychosocial factors, including for instance influences from quality of leadership.

\section{ACKNOWLEDGEMENTS}

The authors would like to express our gratitude to the two ferry shipping companies, and the individual employees of these companies who participated in our study.

\section{REFERENCES}

1. Ahsberg E. Dimensions of fatigue in different working populations. Scand J Psychol. 2000; 41(3): 231-241, doi: 10.1111/14679450.00192, indexed in Pubmed: 11041305.

2. Åhsberg E, Garnberale F, Kjellberg A. Perceived quality of fatigue during different occupational tasks Development of a questionnaire. Int J Industr Ergon. 1997; 20(2): 121-135, doi: 10.1016/s01698141(96)00044-3.

3. Handcock PA, Desmond PA. Stress, workload and fatigue. CRC Press, Taylor \& Francis Group, Boca Raton 2008.

4. Clauw DJ. Perspectives on fatigue from the study of chronic fatigue syndrome and related conditions. PM R. 2010; 2(5): 414-430, doi: 10.1016/j.pmrj.2010.04.010, indexed in Pubmed: 20656623.

5. Janssen N, Kant IJ, Swaen GMH, et al. Fatigue as a predictor of sickness absence: results from the Maastricht cohort study on fatigue at work. Occup Environ Med. 2003; 60 (Suppl 1): i71-i76, doi: 10.1136/oem.60.suppl_1.i71, indexed in Pubmed: 12782750.

6. van Amelsvoort LG, Kant IJ, Beurskens AJ, et al. Fatigue as a predictor of work disability. Occup Environ Med. 2002; 59(10): 712-713, doi: 10.1136/oem.59.10.712, indexed in Pubmed: 12356934.
7. Allen $P$, Wadsworth $E$, Smith A. Seafarers' fatigue: a review of the recent literature. Int Marit Health. 2008; 59(1-4): 81-92, indexed in Pubmed: 19227741.

8. Jepsen J, Zhao Z, Pekcan C, et al. Risk factors for fatigue in shipping, the consequences for seafarers' health and options for preventive intervention. Maritime Psychology. 2017: 127-150, doi: 10.1007/978-3-319-45430-6_6.

9. Barnett M, Pekcan C, Kecklund G, et al. Project MARTHA. The Final Report. Warsash Maritime Academy: Southampton Solent University; 2017. https://www.su.se/polopoly_fs/1.410319.1542102856!/menu/ standard/file/Project\%20MARTHA\%20the\%20final\%20report.pdf.

10. Barnett M, Gatfield D. The use of linked simulators in project "HORIZON": research into seafarer fatigue. International conference on marine simulation and ship manoeuvrability (MARSIM): Singapore Maritime Academy; 2012. http://ssudl.solent.ac.uk/2302/.

11. Smith AP. An update on stress, fatigue and wellbeing: implications for naval personnel. Int Marit Health. 2019; 70(2): 132-139, doi: 10.5603/IMH.2019.0021, indexed in Pubmed: 31237674.

12. BBC Home. Hundreds trapped as car ferry capsizes 1987. Available from: http://news.bbc.co.uk/onthisday/hi/dates/stories/march/6/ newsid_2515000/2515923.stm (Accessed 24th September 2019).

13. Sparks PJ. Questionnaire survey of masters, mates, and pilots of a State Ferries System on health, social, and performance indices relevant to shift work. Am J Ind Med. 1992; 21(4): 507-516, doi: 10.1002/ajim.4700210406, indexed in Pubmed: 1580255.

14. BBC News. $P \& O$ ferry crew fatigue 'poses danger' on Dover-Calais route 2012. Available from. http://www.bbc.com/news/uk-englandkent-19366359 (Accessed 24th September 2019).

15. Sąlyga J, Kušleikaitè M. Factors influencing psychoemotional strain and fatigue, and relationship of these factors with health complaints at sea among Lithuanian seafarers. Medicina (Kaunas). 2011; 47(12): 675-681, indexed in Pubmed: 22370467.

16. Chen GX, Sieber WK, Lincoln JE, et al. NIOSH national survey of long-haul truck drivers: Injury and safety. Accid Anal Prev. 2015; 85: 66-72, doi: 10.1016/j.aap.2015.09.001, indexed in Pubmed: 26397196.

17. Reis C, Mestre C, Canhão $\mathrm{H}$. Prevalence of fatigue in a group of airline pilots. Aviat Space Environ Med. 2013; 84(8): 828-833, doi: 10.3357/asem.3548.2013, indexed in Pubmed: 23926658.

18. Bültmann U, Kant I, KasI SV, et al. Fatigue and psychological distress in the working population: psychometrics, prevalence, and correlates. J Psychosom Res. 2002; 52(6): 445-452, doi: 10.1016/ s0022-3999(01)00228-8, indexed in Pubmed: 12069868.

19. Lewis G, Wessely $\mathrm{S}$. The epidemiology of fatigue: more questions than answers. J Epidemiol Community Health. 1992; 46(2): 92-97, doi: 10.1136/jech.46.2.92, indexed in Pubmed: 1583440.

20. Ricci JA, Chee E, Lorandeau AL, et al. Fatigue in the U.S. workforce: prevalence and implications for lost productive work time. J Occup Environ Med. 2007; 49(1): 1-10, doi: 10.1097/01. jom.0000249782.60321.2a, indexed in Pubmed: 17215708.

21. Dohrmann SB, Leppin A. Determinants of seafarers' fatigue: a systematic review and quality assessment. Int Arch Occup Environ Health. 2017; 90(1): 13-37, doi: 10.1007/s00420-016-1174-y, indexed in Pubmed: 27804037.

22. Oldenburg M, Hogan B, Jensen HJ. Systematic review of maritime field studies about stress and strain in seafaring. Int Arch Occup Environ Health. 2013; 86(1): 1-15, doi: 10.1007/s00420-0120801-5, indexed in Pubmed: 22915144.

23. de Lange AH, Kompier MAJ, Taris TW, et al. A hard day's night: a longitudinal study on the relationships among job demands and job control, sleep quality and fatigue. J Sleep Res. 2009; 18(3): 374-383, doi: 10.1111/j.1365-2869.2009.00735.x, indexed in Pubmed: 19493298 
24. Techera U, Hallowell M, Stambaugh N, et al. Causes and consequences of occupational fatigue: meta-analysis and systems model. J Occup Environ Med. 2016; 58(10): 961-973, doi: 10.1097/ JOM.0000000000000837, indexed in Pubmed: 27525527.

25. Häusser J, Mojzisch A, Niesel M, et al. Ten years on: A review of recent research on the Job Demand-Control (-Support) model and psychological well-being. Work \& Stress. 2010; 24(1): 1-35, doi: $10.1080 / 02678371003683747$.

26. Karasek R. Job Demands, Job Decision Latitude, and Mental Strain: Implications for Job Redesign. Adm Sci Q. 1979; 24(2): 285, doi: 10.2307/2392498.

27. Van der Doef M, Maes S. The job demand-control (-support) model and psychological well-being: a review of 20 years of empirical research. Work Stress. 1999; 13(2): 87-114, doi: 10.1080/026783799296084.

28. Tedesco LM, Ferrara P, Stromillo L, et al. Seafarers' perceptions of job demand: A cross-sectional study. Arch Environ Occup Health. 2018; 73(5): 278-283, doi: 10.1080/19338244.2017.1342590, indexed in Pubmed: 28622113.

29. Hystad SW, Saus ER, Sætrevik B, et al. Fatigue in seafarers working in the offshore oil and gas re-supply industry: effects of safety climate, psychosocial work environment and shift arrangement. Int Marit Health. 2013; 64(2): 72-79, indexed in Pubmed: 23788223.

30. Pereira D, Elfering A. Social stressors at work, sleep quality and psychosomatic health complaints-a longitudinal ambulatory field study. Stress Health. 2014; 30(1): 43-52, doi: 10.1002/smi.2494, indexed in Pubmed: 23824588.

31. von El, Altman DG, Egger M, et al. The strengthening the reporting of observational studies in epidemiology (STROBE) statement: guidelines for reporting observational studies. Int J Surg. 2014; 12 : 1495-1499, doi: 10.1016/j.jclinepi.2007.11.008.

32. Datatilsynet. Persondataloven. Datatilsynet 2000.

33. National Videnskabsetisk Komité. Vejledning om anmeldelse, indberetningspligt mv. (sundhedsvidenskabelige forskningsprojekter). Nationale Videnskabsetisk Komité; 2014.31.

34. Datatilsynet. Samtykke. Datatilsynet 2000.

35. Brislin RW. Back-Translation for cross-cultural research. J Cross Cult Psychol. 1970; 1(3): 185-216, doi: 10.1177/135910457000100301.

36. Pejtersen JH, Kristensen TS, Borg V, et al. The second version of the Copenhagen Psychosocial Questionnaire. Scand J Public Health. 2010; 38(3 Suppl): 8-24, doi: 10.1177/1403494809349858, indexed in Pubmed: 21172767.

37. Oldenburg M, Jensen HJ, Latza U, et al. Seafaring stressors aboard merchant and passenger ships. Int J Public Health. 2009; 54(2): 96-105, doi: 10.1007/s00038-009-7067-z, indexed in Pubmed: 19288290.

38. Kirkwood BR, Sterne JAC. Analysis of clustered data. Essential Medical Statistics. Blackwell Science, Massachusetts 2005.

39. Streiner DL, Norman GR, Cairney J. Health measurement scales. A practical guide to their development and use. Oxford University Press, Oxford 2015.

40. Kant IJ, Bültmann U, Schröer KAP, et al. An epidemiological approach to study fatigue in the working population: the Maastricht Cohort Study. Occup Environ Med. 2003; 60(Suppl 1): i32-i39, doi: 10.1136/ oem.60.suppl_1.i32, indexed in Pubmed: 12782745.

41. Færge Rederierne. Færge Rederiernes Årsberetning 2018. Færge Rederierne; 2018.

42. Leung AWS, Chan $\mathrm{CCH}, \mathrm{Ng} J \mathrm{JM}$, et al. Factors contributing to officers' fatigue in high-speed maritime craft operations. Appl Ergon. 2006;
37(5): 565-576, doi: 10.1016/j.apergo.2005.11.003, indexed in Pubmed: 16368069.

43. de Lange AH, Taris TW, Kompier MAJ, et al. "The very best of the millennium": Iongitudinal research and the demand-controI-(support) model. J Occup Health Psychol. 2003; 8(4): 282-305, doi: 10.1037/1076-8998.8.4.282, indexed in Pubmed: 14570524.

44. Cohen S, Wills T. Stress, social support, and the buffering hypothesis. Psychological Bulletin. 1985; 98(2): 310-357, doi: 10.1037/00332909.98.2.310.

45. Allen $\mathrm{P}$, Wadsworth $\mathrm{E}$, Smith $\mathrm{A}$, et al. The prevention and management of seafarers' fatigue: a review. Int Marit Health. 2007; 58(1-4): 167-177, indexed in Pubmed: 18350986.

46. Rugulies R. Invited commentary: Structure and context matters-the need to emphasize "social" in "psychosocial epidemiology". Am J Epidemiol. 2012; 175(7): 620-624, doi: 10.1093/aje/kws033, indexed in Pubmed: 22392474.

47. de Jonge J, Kompier M. A critical examination of the demandcontrol-support model from a work psychological perspective. Int J Stress Manag. 1997; 4(4): 235-258, doi: 10.1023/b:ijsm.0000008152.85798.90.

48. Wadsworth EJK, Allen PH, Wellens BT, et al. Patterns of fatigue among seafarers during a tour of duty. Am J Ind Med. 2006; 49(10): 836-844, doi: 10.1002/ajim.20381, indexed in Pubmed: 16948149.

49. Lazarrus RS. Folkman S. Stress, appraisal, and Coping. Springer, New York 1984.

50. Doyle N, MacLachlan M, Fraser A, et al. Resilience and well-being amongst seafarers: cross-sectional study of crew across 51 ships. Int Arch Occup Environ Health. 2016; 89(2): 199-209, doi: 10.1007/ s00420-015-1063-9, indexed in Pubmed: 26062930.

51. McVeigh J, MacLachlan M, Vallières $F$, et al. Identifying Predictors of Stress and Job Satisfaction in a Sample of Merchant Seafarers Using Structural Equation Modeling. Front Psychol. 2019; 10: 70, doi: 10.3389/fpsyg.2019.00070, indexed in Pubmed: 30787888.

52. Bambra C, Egan M, Thomas S, et al. The psychosocial and health effects of workplace reorganisation. 2. A systematic review of task restructuring interventions. J Epidemiol Community Health. 2007; 61(12): 1028-1037, doi: 10.1136/jech.2006.054999, indexed in Pubmed: 18000123.

53. Egan M, Bambra C, Thomas S, et al. The psychosocial and health effects of workplace reorganisation. 1. A systematic review of organisational-level interventions that aim to increase employee control. J Epidemiol Community Health. 2007; 61(11): 945-954, doi: 10.1136/jech.2006.054965, indexed in Pubmed: 17933951.

54. Joyce S, Modini M, Christensen $\mathrm{H}$, et al. Workplace interventions for common mental disorders: a systematic meta-review. Psychol Med. 2016; 46(4): 683-697, doi: 10.1017/S0033291715002408, indexed in Pubmed: 26620157.

55. Joyce K, Pabayo R, Critchley JA, et al. Flexible working conditions and their effects on employee health and wellbeing. Cochrane Database Syst Rev. 2010(2): CD008009, doi: 10.1002/14651858. CD008009.pub2, indexed in Pubmed: 20166100.

56. Hartzler BM. Fatigue on the flight deck: the consequences of sleep loss and the benefits of napping. Accid Anal Prev. 2014; 62: 309-318, doi: 10.1016/j.aap.2013.10.010, indexed in Pubmed: 24215936.

57. Kogi K. International research needs for improving sleep and health of workers. Ind Health. 2005; 43(1): 71-79, doi: 10.2486/indhealth.43.71, indexed in Pubmed: 15732307. 